fundamental work of the Greenwich Time Service, and it has now attained a high standard of reliability. Introduced at first in the Greenwich Time Service as long-term standards, their high stability over periods of two or three years has made it possible to use them for determining the nature of the annual fluctuations in the rotation of the earth. It is worth noticing that the periods of uninterrupted run, given continuity of power supplies, may extend over several years, as has been the case with some of the clocks mentioned. Failure of crystal oscillators is very rare-in six years since the Abinger clocks were transferred to battery operation there has been only one failure of a crystal oscillator.

\section{Index of Theses for Higher Degrees at British Universities}

Is a paper prepared for presentation to a conference of the Association of Special Libraries and Information Bureaux which was to have been held at Nottingham during September 1939, Colonel Luxmoore Newcombe discussed the accessibility of British university theses and the need for more information about such theses, and went on to raise the question of the feasibility of compiling and publishing a national guide to such theses. Fourteen years later, as a result of discussions of a joint subcommittee appointed early in 1950 by the Library and Information Committee of Aslib and the University and Research Section of the Library Association, this suggestion has come to fruition in a new serial publication of Aslib, "Index to Theses Accepted for Higher Degrees in the Universities of Great Britain and Ireland" (Vol. 1, 1950-51 ; pp. xii +157. London: Aslib, $1953 ; 25 s$, or $21 s$. to members). This first volume, which is edited by P. D. Record, covers the academic year 1950-51, except for the University of London, where entries are based on the calendar year 1950. The material has been supplied by the Secretary to the Committee of Vice-Chancellors and Principals, and the Index covers theses accepted by universities in England, Wales, Scotland, Northern Ireland and the Republic of Ireland. Information on availability is summarized in a table appended to an editorial note, and an introduction is contributed by Mr. J. H. P. Pafford. The present volume covers 2,182 theses, and the entries are numbered serially and arranged by subjects, the author's name being given first, followed by the title and the degree for which it is given. The author's university is indicated by an initial letter or letters in parentheses, following his name. An index of authors and a subject index are provided; but the latter, like the classification of the entries, as the editorial note emphasizes, is subject to the hazards and limitations imposed by the absence of any other information as to content beyond that supplied by the titles of the theses.

\section{Radio Instruments and Preferred Valves}

THE firm of Marconi Instruments, Ltd. (St. Albans, Herts), has recently published a bound catalogue describing and illustrating a large variety of its instruments for those engaged in telecommunications and allied industrial applications. This catalogue is the first of an annual series, and it supersedes the looseleaf versions which have been issued by the company during the past few years. Among the new instruments described in the present volume are : a series of portable absorption-type frequency-meters covering the range 250-4,000 Mc./s.; a very-high-frequency test set, comprising a signal generator covering frequencies 60-200 Mc./s., power meters for audio and radio frequencies, a radio-frequency field detector, and a multi-range D.c. test meter; and a useful oscillator providing a signal power of about 10-50 $\mathrm{mW}$. over the frequency-range $2,100-3,750 \mathrm{Mc} / \mathrm{s}$. Most of the instruments shown in the section on "Television and Radar Test Equipment" are new, and they include a test set for the $3-\mathrm{cm}$. band $(9,000-9,680 \mathrm{Mc} / \mathrm{s}$.$) , and a spectrum analyser and$ noise generator for the $10-\mathrm{cm}$. band $(2,900-3,150$ Mc./s.). In order that users of this catalogue may keep up to date with developments in measuring technique, a useful bulletin entitled "Marconi Instrumentation" is issued at frequent intervals and may be obtained on request.

Another most useful publication, which has recently become available, is a booklet entitled "List of Preferred Valves", which has been issued by the Scientific Instrument Manufacturers' Association (20 Queen Anne Street, London, W.1). This comprises in tabular form details of the types and characteristics of a series of valves which, it is believed, will meet most of the needs of those engaged in the scientific instrument industry. The list is divided into two categories-standard-sized valves and miniature valves-and details of the base-connexion arrangements for each type are included.

\section{"Life in A.D. 2000": Royal Society of Arts Bicentenary Competition}

THE Royal Society of Arts will reach its bicentenary in March 1954, and as part of the celebration of this event the Society is organizing an essay competition with prizes of $£ 250, £ 100, £ 50$ and ten of $£ 10$, making a total of $£ 500$. The general subject for the essays is : "The Practical Aspects of Life on this Earth in the Year 2000", and individual competitors are required to submit their forecasts of a single aspect of life at that period related to arts, manufacture or commerce. Entries may be in written or be in visual form (drawings or models, with any necessary explanation in writing); in the former case they must be typewritten and in English and must not exceed three thousand words. The competition is open to all persons of British nationality and Fellows and Associates of the Society of whatever nationality. Competitors must complete an entry form by February 15, 1954, and must submit their essays by June 30. Further details can be obtained from the Secretary, Royal Society of Arts, John Adam Street, Adelphi, London, W.C.2.

\section{History of Regional Farming in Britain}

THE Association of Agriculture and the British Agricultural History Society are arranging a one-day conference to discuss regional history with special emphasis on the agricultural background, to be held at the Institute of Education of the University of London, Malet Street, London, W.C.1, at 10.30 a.m. on December 5. The first paper will be a general one on "Regional Farming in England", by Dr. W. G. Hoskins. The afternoon session will be devoted to three short papers on "The Farming Regions of Lincolnshire", by Mrs. I. J. Thirsk ; "The Rise of Sheep Farming with the Great Enclosures in North Wales", by Prof. R. Alun Roberts; and "Farming Regions with Special Reference to Wiltshire", by 